Center for Philosophical Investigations

Faculty of Humanities and Educational Sciences

La Plata National University

vicentesofia@yahoo.com.ar

\title{
THE B SIDE OF IMAGINATION. HUME ON IMPERFECT IDEAS
}

\begin{abstract}
M y$ aim is to look into the representational aspect of ideas, exploring not only to what Hume refers as adequate ideas, but also these cases where for a number of reasons an idea does not reach that standard. It has been suggested that the latter are fictions, but an in-depth examination of Hume texts reveals that there are several types of imperfections, such as incompleteness or imprecision that prevent an idea from being adequate. This leads to an analysis of the status of supposed or pretended ideas, and the possibility of there being terms with no ideas annexed to them.
\end{abstract}

Keywords: Adequate ideas, fictions, supposed ideas, empty terms, representation

\section{Introduction}

In his recent book, The Imagination in Hume's Philosophy (2018), Timothy Costelloe offers an organized and systematic view about the workings of imagination in all of Hume's writings. Throughout the book, a distinction emerges between fictions and genuine ideas $(2018,30)$ which guides many of Costelloe's arguments.

The distinction develops as a result of examining two different powers of imagination: the mimetic and the productive $(2018,6)$. The mimetic power is related to the capacity of imagination to copy impressions in a similar way as memory does (T 1.1.3.1; SBN 8-9, EHU 2.2; SBN 17-18), ${ }^{1}$ which provides reason and understanding the ideas they work with $(2018,6-7)$. The productive power, Costelloe argues, belongs to imagination understood in a narrow sense, that is, as excluding demonstrative and probable reasoning ( $\mathrm{T}$ 1.3.9.19 n22, SBN 117-118). It has two sides: one combinatory and another creative. The former exhibits the power of imagination to combine, separate, rearrange, and change its stock of ideas in all possible ways to create new ideas (T 1.1.3.4, SBN 10; EHU 2.5, SBN 19; 5.10, SBN 47-48; 5.12, SBN 48$50)$. The latter refers to the capacity to create original ideas independently of experience and according to imagination's inner logic $(2018,21){ }^{2}$ Thus, the

1 All works by Hume will be cited using abbreviations referenced in the Bibliography.

2 Costelloe states that the creative aspect of imagination is revealed when Hume argues that anyone can produce the idea of the missing shade of blue even though "it had never been convey'd to him by his senses" (T 1.1.1.10, SBN 5-6). Costelloe observes that the 
productive aspect of imagination reflects the possibility to conceive objects that cannot be traced directly to an impression $(2018,25)$.

According to Costelloe, ideas that do not have a direct correlation with impressions spring up from certain operations of imagination, which slides easily from experience to what Hume sometimes refers to as „suppositions, “i. e. something that is taken as if it were the case even though it has not been perceived or lacks justification $(2018,24)$. As a consequence of this easy transition, the imagination produces errors $(2018,25)$. Costelloe regards fictions as a type of error formed through the productive aspect of imagination $(2018,29)$.

Costelloe's distinction between genuine ideas and fictions is suggestive because it focuses not only on full-blooded ideas, but also on what does not quite fit in that place. However, when reviewing Hume's texts, it is not clear that the distinction between genuine ideas and those that are not genuine is exhaustive. Instead, we find a series of names for ideas that do not reach a desired standard: non-adequate, imperfect, supposed or pretended ideas. Despite what Costelloe argues, this does not necessarily entail all these ideas are errors, nor that they are detached from matters of fact either. It shows that for various reasons, they do not reach the status of genuine ideas. And the reasons offered to show that an idea is not genuine are different in each case, what lead us to suspect they cannot be considered fictions alike. Hume, as usual, does not present this sort of taxonomy of ideas systematically; hence difficulties arise when trying to reconstruct it in an organised way.

The different types of "imperfections" which prevent an idea from being genuine merit a deeper investigation. I first explain what makes an idea genuine, and then turn to those cases where these requirements cannot be met. This reveals that the differences between the various types of imperfect ideas are related to several representational problems between ideas and their objects. Finally, I trace some of the consequences of these problems at a semantic level, by means of examining the connection between imperfect ideas and ambiguous terms.

\section{Adequate ideas}

First of all, I want to make clear that the expression "genuine idea" is Costelloe's and not Hume's. When Hume refers to a full-blooded idea, he calls it „adequate idea“ instead. Therefore, I will turn to Humean terminology and proceed to study the nature of these perceptions.

The notion of adequate idea or adequate knowledge was common in Early Modern philosophy. Roughly speaking -although there are differences among authors such as Descartes, Leibniz, Locke or Spinoza- it refers to adequate representations of objects, in the sense that any attribute of an adequate idea is also an attribute of the object it represents (Lightner 1997, 117). Hume does

creative aspect of imagination has not been noticed by commentators, with the exception of Donald Ainslie $(2015,64)$. 
not explicitly define what he means by an adequate idea, and there are some nuances expressed by the interpreters in this regard. Donald Ainslie (2010, $41 ; 2015,69)$ relates Hume's notion of adequate idea to that of Descartes and Locke, understanding it as an idea that "fully capture [its] object[s]." In a similar vein, Peter Kail (2003, 52-53), argues that, in line with Locke, Hume considers that adequate ideas offer all the relevant information of an object, in the sense of reflecting its internal structure or complete essence. Tycerium Lightner $(1997,121)$, on the other hand, states that Hume uses "adequate," to mean "clear and distinct." This, in fact, is not incompatible with the definition proposed by Ainslie and Kail, since an idea that fully captures its object is, after all, a clear and distinct idea. As I will show below, the adequate character of an idea resides not only in its completeness (i. e. that it can fully represent its object) but also in its precision (i. e. that it is able to represent its object's attributes in a distinct and precise way).

When defining adequate ideas, scholars frequently rely on the passage where Hume states: "Wherever ideas are adequate representations of objects, the relations, contradictions and agreements of the ideas are all applicable to the objects" (T 1.2.2.1, SBN 29). Setting aside the various interpretations this passage has been subject to, I wish to remark how the passage shows that, like other modern philosophers, Hume relates adequacy to the representational ability of an idea. Of course, determining what Hume intends as an object would merit a separate work. I restrict myself to pointing out that if by an object we understand the impression(s) that the idea copies, then an idea could be an adequate representation of its object. But as Kail $(2003,56 \mathrm{n} 23)$ observes, if by an object we mean an in re object, we cannot have an adequate impression of it, nor therefore an adequate idea, since we cannot conceive of it as something specifically different from a perception (T 1.2.6.8, SBN 67-8).

Hume touches on adequate ideas in the Dialogues concerning Natural Religion when considering the possibility of knowing divine nature and attributes. This text has been overlooked by scholars who dealt with the subject, but it offers extra evidence to clarify the features of completeness and precision I mentioned above. Cleanthes aims at attaining an adequate idea of the Divine mind from its supposed similarity to the human mind. By means of the argument from design, he transfers the similarity between the products of human contrivance and the order of the universe, to a supposed similarity between their causes. Nevertheless, from Demea's mystical perspective, human nature is incommensurable with Divine nature. This means that there is no way of knowing whether any feature of the former can be similar to the latter so as to achieve, by means of analogy, an adequate idea of Divinity:

Your instance, Cleanthes, said he [Demea], drawn from books and language, being familiar, has, I confess, so much more force on that account; but is there not some danger too in this very circumstance; and may it not render us presumptuous, by making us imagine we 
comprehend the Deity, and have some adequate idea of his nature and attributes? When I read a volume, I enter into the mind and intention of the author: I become him, in a manner, for the instant; and have an immediate feeling and conception of those ideas, which revolved in his imagination, while employed in that composition. But so near an approach we never surely can make to the Deity. His ways are not our ways. His attributes are perfect, but incomprehensible (DNR 3.11, KS 155-6).

Cleanthes' argument relies on one of the relevant conditions for an idea to represent an object, which is resemblance (Garrett 2006, 308). In this case we cannot have an impression of the Divine attributes for obvious reasons, but Cleanthes believes that this difficulty can be overcome by appealing to the similarity between their effects and those belonging to a mind whose impression we do have: the human. This means that if we can have an adequate idea of the human mind from the works of its contrivance, we can have an adequate idea of the divine mind from His creation. Demea, in turn, argues against the legitimate character of this similarity. Don Garrett $(2006,309)$ points out that, in addition to resemblance, there is a second condition that amounts to representation. This condition is causal derivation, since Hume affirms that "ideas always represent the objects or impressions from which they are derived" (T 1.2.3.11, SBN 37). Demea's mystical perspective would allow God being the immediate cause of the idea we have of Him (since, again, we can have no impression of that idea), but this possibility does not seem to grant that our idea represents His nature adequately. Unlike causal derivation, resemblance seems to be in this case a crucial condition to entertain an adequate idea of a certain object. As long as there is nothing in the divine attributes that resembles ours, it is not possible to attain an adequate idea of them, because there are no means of establishing a comparison between both. Cleanthes, on the other hand, claims that even though we can establish a limited similarity only, this amounts to an adequate idea of God:

It seems strange to me, said Cleanthes, that you, Demea, who are so sincere in the cause of religion, should still maintain the mysterious, incomprehensible nature of the Deity, and should insist so strenuously, that he has no manner of likeness or resemblance to human creatures. The Deity, I can readily allow, possesses many powers and attributes, of which we can have no comprehension: But if our ideas, so far as they go, be not just, and adequate, and correspondent to his real nature, I know not what there is in this subject worth insisting on. Is the name, without any meaning, of such mighty importance? (DNR 4.1, KS 158)

Cleanthes admits that the similarity between God and His creatures is not complete. But this fact does not seem to preclude us from having an adequate idea of Him, that is, an idea that corresponds to His „real nature." Even 
though there are many divine attributes that exceed our cognitive capacity, the resemblance between certain Divine and human attributes has been legitimately demonstrated by the argument from design. This grants that our idea of God is adequate. From Cleanthes's perspective, then, an idea that is admittedly incomplete, since it does not "fully capture [its] object," can be adequate, after all; whereas from Demea's point of view, if an idea is incomplete, it cannot be adequate.

So far, the Dialogues leave us with two possible ways of understanding an adequate idea, reflected in Demea's and Cleanthes' positions. There is no way of being certain about which of the characters represent Hume's position, or even if it is represented by any of them at all. However, they present us with a spectrum of possibilities that can be confronted with other texts to see if Hume assumes some of their features as his own explicit view. Let us turn to the Treatise in order to do so:

First then I observe, that when we mention any great number, such as a thousand, the mind has generally no adequate idea of it, but only a power of producing such an idea, by its adequate idea of the decimals, under which the number is comprehended. This imperfection, however, in our ideas, is never felt in our reasonings ( $\mathrm{T}$ 1.1.7.12, SBN 22-23).

In this passage, Hume seems to understand adequate ideas in terms of representations that fully capture their objects, in line with Demea's perspective. But unlike the idea of God, in this case the object represented falls within the scope of experience. This grants we can have an impression of it. Thus, the difficulty in achieving an adequate representation does not lie in the incommensurability between the object and the idea that stands for it. The idea of a thousand is not adequate because it is difficult to verify whether the units we envision actually reach that amount. However, Hume claims that we can generate an approximate and imperfect representation of a great number with the help of an adequate idea. The adequate idea of a decimal, when replicated a number of times, allows us to understand the notion of a thousand, since the units that make up a certain number, be it ten, be it a thousand, are identical. We can notice, then, that inadequate ideas are not necessarily errors. As Ainslie argues $(2015,69)$, they may be sufficient for some purposes; such as to represent a large amount. If needed, we are endowed with the cognitive skills to be more precise and generate an idea that represents a thousand units.

Later on, Hume offers another example concerning the difficulty of having adequate ideas of extremely small animals such as a mite. It is important to notice that the previous example belongs to mathematics, where ideas are always "clear and determinate " and have univocal or at least stable definitions. This sort of definitions can help us verify, eventually, the completeness of the representation (EHU 7.1, SBN 60). The mite example belongs to matters of fact, where we are deprived of this possibility: 
This however is certain, that we can form ideas, which shall be no greater than the smallest atom of the animal spirits of an insect a thousand times less than a mite: And we ought rather to conclude, that the difficulty lies in enlarging our conceptions so much as to form a just notion ${ }^{3}$ of a mite, or even of an insect a thousand times less than a mite. For in order to form a just notion of these animals, we must have a distinct idea representing every part of them; which (...) is extremely difficult, by reason of the vast number and multiplicity of these parts (T 1.2.1.5, SBN 28).

In this passage Hume points out that in order to have an adequate idea of minute creatures or objects, we must be able to conceive distinct ideas of each and every one of its parts, which is „extremely difficult.“ The idea of a mite is an extremely complex idea, because it is made up of a large amount of simple ideas. Even though imagination is able to form these kinds of ideas, the difficult thing is to verify whether we include not only all the parts that make it up, as with the idea of great numbers, but also, that we have a distinct idea of each of them. Unlike the concept of a thousand, we cannot formulate a definition that exhaustively describes the parts of a mite, let alone suppose that all of them are identical, which would allow us to suppose that by knowing some of its parts, we can have an idea of the whole, as in the case of the units that make up a great number. Nothing prevents us from thinking that a scientist may discover unknown parts of this animal using a powerful microscope (see T 1.2.1.4, SBN 27-8). In this case, thus, the idea is not adequate not only because it is incomplete but also because it is imprecise.

So far, textual evidence suggests that adequacy consist in two aspects: precision and completeness. If we guarantee the ideas we have are distinct then, although we cannot know for sure whether they fully reflect their object, we may reach a limited adequacy of the kind Cleanthes proposes. If we also guarantee that the idea is complete, we can have a fully adequate idea, which matches Demea's requisites. But as the examples from the Treatise suggest, the two aspects of adequacy can only be achieved by -or at least, be verified in- objects belonging to the realm of relations of ideas, simple ideas of sensation or ideas of relatively low complexity.

Up to this point we can see that one of the main problems concerning adequate ideas consists in what Ainslie names the "epistemological challenge" $(2010,41)$. Ainslie argues that, unlike Descartes and Locke, Hume claims that adequacy of ideas does not refer to in re objects but to perceptual objects $(2010,61)$. However, even if we admit that the representational character of an idea refers to a perceptual object, this fact does not guarantee per se the possibility of fully determining their adequacy. The methodological use of

3 Although Hume is using here the term "just", at the beginning of the paragraph he talks about forming "adequate ideas", so at least in this case he is using "just" as a synonym for "adequate." 
the copy principle $e^{4}$ can only solve the problem in part, because it allows us to deal with issues related to precision, but not to completeness. Hume asserts that impressions are always clear and distinct, and therefore incontrovertible, while ideas are usually obscure because they are weaker or fainter than impressions. As is well known, the copy principle allows us to clarify ideas by showing their connection with the impressions that caused them:

By what invention can we throw light upon these ideas, and render them altogether precise and determinate to our intellectual view? Produce the impressions or original sentiments, from which the ideas are copied. These impressions are all strong and sensible. They admit not of ambiguity. They are not only placed in a full light themselves, but may throw light on their correspondent ideas, which lie in obscurity. And by this means, we may, perhaps, attain a new microscope or species of optics, by which (...) the most minute, and most simple ideas may be so enlarged as to fall readily under our apprehension, and be equally known with the grossest and most sensible ideas, that can be the object of our enquiry (EHU 7.4, SBN 62).

The copy principle begins with ideas and proceeds backwards, towards their origin, by means of analysis or decomposition. This proceeding can concede greater precision to ideas of minute animals such as a mite, „enlarging“ our complex ideas to achieve a precise and distinct vision of the simple ideas that compose it, relating these simple ideas to the impressions that caused them. But the copy principle cannot reveal if the complex idea of the mite fully captures its object, i.e., it does not show if there are any impressions left; it just helps us realize if the ideas we envision are clear and precise. This problem, as indicated by Kail $(2003,49-50)$ and Ainslie $(2010,43)$ is reminiscent of what Locke says concerning the inadequacy of our ideas of substances, i. e. that it is impossible for them to include representations of all their qualities (E 2.31.11). ${ }^{5}$ Although, unlike Locke, Hume denies that our ideas can represent anything different from perceptions, the possibility that our complex ideas do not "fully capture their objects" persists. He himself suggests it when he says: "I have seen Paris; but shall I affirm I can form such an idea of that city, as will perfectly represent all its streets and houses in their real and just proportions?" (T 1.1.1.4, SBN 3). Apparently, then, there is no way to fulfil the completeness requirement, at least in the case of complex ideas concerning matters of fact. This brings Hume's position closer to Cleanthes's than to Demea's: his references to adequate ideas should be understood in a limited sense.

4 I refer to the methodological use of the copy principle following Garrett's suggestion $(1997,73)$, in the sense that it can be used as "the support for a methodological directive concerning problematic ideas."

5 Locke's work will be cited using abbreviations referenced in the Bibliography. 


\section{Fictions and supposed ideas}

We can move now to those ideas Hume regards as "imperfect" (T 1.1.7.12, SBN 22-3) in order to study why they fall short of being adequate. In the introduction I pointed out that fictions are one type of imperfect ideas, but not the only one. Let us see, in the first place, why at least certain kinds of fictions can be considered imperfect ideas, and then examine the case of supposed or pretended ideas.

As some authors point out (Traiger 1987, 395; Ainslie 2015, 83), Hume does not have a completely negative view of fictions, but rather of certain fictions that philosophers construct and apply, such as occult qualities or sympathies and antipathies. There are other fictions, which have been called „natural“ (Traiger 1987, 395; Costelloe, 2018, 33-4) because they arise from the regular motions of imagination, such as the easy transition principle. Among them we can mention personal identity, substance, the distinct and continuous existence of objects, duration of unchanging objects, and perfect standards, to name a few. These natural fictions fulfil certain epistemic and practical functions relevant to the development of everyday life. Philosophical fictions, on the contrary, fall within what Costelloe (2018, 31-2) calls "artificial fictions," which are the product of an individual's imagination. ${ }^{6}$ They stem from a voluntary act of the imagination that can combine and create new ideas that do not directly correspond to matters of fact and existence.

Even though different types of fictions can be distinguished in Hume's texts, they all share a distinct feature: they are ideas applied to something from which they could not have been derived (Traiger 1987, 385-386; Ainslie 2015, 66; Costelloe 2018, 30). Thus, Hume claims: "Ideas always represent the objects or impressions, from which they are deriv'd, and can never without a fiction represent or be apply'd to any other" (T 1.2.3.11, SBN 37). A few lines before he states that, with respect to the idea of duration applied to an unchanging object, „,it can never in any property or exactness be applied to it" (T 1.2.3.11, SBN 37). As Saul Traiger notices (1987, 386), in this passage Hume relates the imperfect character of a fiction to its being improper, because it arises in one context and is improperly applied to another. The idea of duration is never derived from an unchanging object, but from the comparison between that object and the incessant flow of our perceptions. The fiction consists of applying that idea, which derives from constant movement, to a static object. Ainslie $(2015,75)$ calls this the "idea-substitution mechanism," and describes it as an operation of the imagination where an idea is inserted in the place of another without our realizing it. As I mentioned above, Hume does not hold a negative view of this mechanism, because he regards it as natural. What Hume condemns is that certain philosophers omit this substitution mechanism carried out by

6 Costelloe $(2018,29-36)$ develops a detailed analysis of the different types of fictions. 
the imagination and assume that the ideas in question are indeed derived from such objects (Traiger 1987, 386) or else they intend to apply them to non-perceptual objects (Ainslie 2015, 83, 106).

The reason why Hume considers (at least some) fictions as imperfect ideas is different from the ones mentioned in the previous section. The decisive feature in this case is not imprecision or incompleteness, but impropriety, that is, the fact that the idea supposedly represents an object that it cannot represent. This means that a fiction does not meet the requirement of causal dependence: it could not have been derived from the object we improperly intend to apply it. If we recall the relevant conditions that amount to the representational character of an idea, we can relate completeness and precision to resemblance, and property to causal dependence. When any of these conditions fails, the result is an imperfect idea.

In addition to the fictions already mentioned, Garrett (2006, $313 \mathrm{n} 17)$ recognizes another type of fictions he considers more philosophically objectionable: "we take ourselves to have ideas meeting certain representational conditions -in the case of 'substance' for example, the condition of representing something that unites complex and interrupted items into something simple and identical- without having any idea at all ( $\mathrm{T}$ 1.1.6.1; $\mathrm{T}$ 1.4.3)." Nevertheless, I think that regarding this case as a type of fiction is troublesome; because it entails assuming we have an idea when in fact we have no idea at all, and Hume never calls into question that fictions are ideas (T 1.3.7.7, SBN 628-29; EHU 5.10-11, SBN 47-8). Let us briefly review the two passages Garrett mentions as textual evidence of this type of fiction. This is the first one:

I wou'd fain ask those philosophers, who found so much of their reasonings on the distinction of substance and accident, and imagine we have clear ideas of each, whether the idea of substance be deriv'd from the impressions of sensation or of reflection? (...) We have therefore no idea of substance, distinct from that of a collection of particular qualities, nor have we any other meaning when we either talk or reason concerning it (T 1.1.6.1, SBN 15-16).

It can be noticed that Hume does not question there is an idea of substance. Rather, he intends to show that it is a fiction in the sense defined above. The notion of substance is nothing but a collection of simple ideas united by the imagination, but philosophers pretend to refer it "to an unknown something, in which they [the qualities] are supposed to inhere; or granting this fiction should not take place, are at least supposed to be closely and inseparably connected by the relations of contiguity and causation" (1.1.6.2, SBN 16). In other words, this is an instance similar to the other cases of fictions we have seen. Then, Garrett sends us to 1.4.3, where Hume continues talking about substance. We find this passage: 
But these philosophers carry their fictions still farther in their sentiments concerning occult qualities, and both suppose a substance supporting, which they do not understand, and an accident supported, of which they have as imperfect an idea (T 1.4.3.8, SBN 222).

Here, Hume regards both substances and occult qualities as fictions, which in turn he considers as imperfect ideas. ${ }^{7}$ This shows that a fiction never loses its status of idea. If we assume we have an idea when in fact we cannot be sure we have it, then we are not entertaining a fiction, but something else. Garrett is correct in acknowledging the existence of this type of philosophically objectionable representational items, but I do not think he is right in classifying them as fictions. These items are what Hume calls „supposed“ or "pretended" ideas, and what I will examine now is whether they are indeed some other type of imperfect ideas or they are something else, in case we do not have „any idea at all.“

Hume mentions these items for the first time in the Abstract and then again in An Enquiry concerning Human Understanding. Both passages have a similar structure. In the former, he refers to them as "pretended ideas." 8 The notion appears when Hume is introducing the methodological use of the copy principle:

Our author thinks, that no discovery cou'd have been made more happily for deciding all controversies concerning ideas than this, that impressions always take the precedency of them, and that every idea, with which the imagination is furnishd, first makes its appearance in a correspondent impression. These latter perceptions are all so clear and evident, that they admit of no controversy; tho' many of our ideas are so obscure, that 'tis almost impossible even for the mind, which forms them, to tell exactly their nature and composition. Accordingly, wherever any idea is ambiguous, he has always recourse to the impression, which must render it clear and precise. And when he suspects that any philosophical term has no idea annexed to it (as is too common) he always asks from what impression that pretended

7 Admittedly, the idea of substance is a particularly difficult case. At T 1.4.5.6, SBN 234, Hume states: "We have no perfect idea of any thing but of a perception. A substance is entirely different from a perception. We have, therefore, no idea of a substance." Although it might seem that he actually affirms there is no idea of substance -which on the other hand would contradict T 1.1.6.1- the context shows that Hume is referring to the philosophical notions of substance as an inhesion substrate, or as something that may exist by itself. David Landy $(2018,107$ n5) argues that Hume is not criticizing the bare notion of substance, but a particular idea of substance „as incorrectly conceived by his predecessors (e. g. Cartesians)." We could then suppose that what Hume means is that there is no perfect idea of substance, since its fictitious character entails it is an imperfect idea. This interpretation makes $\mathrm{T}$ 1.4.5.6 consistent with what he claims at $\mathrm{T}$ 1.4.3.8.

8 Given the similarities between the two passages, I assume the adjectives „supposed“ and „pretended" can be considered equivalent. 
idea is derived? And if no impression can be produced, he concludes that the term is altogether insignificant. 'Tis after this manner he examines our idea of substance and essence; and it were to be wished, that this rigorous method were more practised in all philosophical debates (Abs. 7, SBN 648-9).

In this paragraph we can distinguish two levels: the mental and the linguistic (Ott 2009, 198). At the mental level, Hume deals with the representational relation between ideas and impressions, which can be clarified using the copy principle. At the linguistic level, he deals with the relation between words and ideas, which he describes in terms of annexation. If we assume that the copy principle can trace the origin of an idea, then sooner or later we must find the impression(s) that caused it. This is what Hume states at the beginning of the paragraph: every [simple] idea has as its antecedent a [simple] impression. So, this seems to rule out the possibility that an idea does not originate, directly or indirectly, in an impression. ${ }^{9}$ However, the text does not seem to indicate that the relationship between words and ideas has the same universal character that unites ideas with impressions. ${ }^{10}$ Therefore, if the existence of a word does not necessarily indicate the existence of an idea, it would be possible that terms without attached ideas exist. We might consider these as „empty“ terms or, as Hume calls them, „insignificant.“ A word means an idea, and if there is no such idea, then the word is meaningless. This situation can be verified turning to the copy principle, which cannot directly clarify the relationship between the word and the pretended idea, but rather between the pretended idea and the impression(s) from which it could have been derived. If we cannot find the impression(s) that might have caused the pretended idea, then it seems that the term in question does not have any correlation at the mental level. It is nonsense (Ott 2009, 208-9).

Now, it is important to note that Hume states the proposition where he deals with words-ideas relationship in a conditional mode, since he qualifies it as a suspicion. This means he opens both the possibility of not finding or producing the impression(s) from which that pretended idea would have been derived, as well as the possibility of finding it, which would modify its pretended status for that of a plain idea. This suggests that the category of pretended idea does not necessarily mark a lack of ideas but rather directs our attention to a point that requires clarification. As a result, the examination of pretended ideas can yield an idea (be it adequate or imperfect, depending on the relation it has with the impression(s) found), or no idea at all, in the event

9 Several authors put this strict interpretation of the copy principle into question and remark the creative capacity of the imagination to produce ideas detached from impressions. As stated in footnote 2, among them are Ainslie and Costelloe. Also, the New Humeans propose a broad interpretation of the theory of ideas based on the category of relative ideas (Richman 2000, 3-4). However, in the passages where Hume mentions supposed and pretended ideas, he seems to understand the copy principle in a strict sense.

10 I will return to the semantic issue in the last section. 
that we cannot produce any impression that directly or indirectly caused it. The allusion to substance at the end of the paragraph confirms the former possibility: in this case, the analysis would not lead us to an empty term, as Garrett's interpretation suggests, but to a fictitious idea.

However, there is something awkward in this interpretation of the passage from the Abstract. Hume seems to be applying the copy principle to something whose ideal status is in doubt and may consist of just an empty linguistic term. Would this use of the copy principle be admissible? Should not we be sure to apply the copy principle to an idea, be it obscure or faint, but an idea nonetheless? Let us turn to the second passage, which belongs to the first Enquiry, to see if it helps us clarify this matter. Here, Hume refers to these items as "supposed ideas":

All ideas, especially abstract ones, are naturally faint and obscure: The mind has but a slender hold of them: They are apt to be confounded with other resembling ideas; and when we have often employed any term, though without a distinct meaning, we are apt to imagine it has a determinate idea, annexed to it. On the contrary, all impressions, that is, all sensations, either outward or inward, are strong and vivid: The limits between them are more exactly determined: Nor is it easy to fall into any error or mistake with regard to them. When we entertain, therefore, any suspicion, that a philosophical term is employed without any meaning or idea (as is but too frequent), we need but enquire, from what impression is that supposed idea derived? And if it be impossible to assign any, this will serve to confirm our suspicion. By bringing ideas into so clear a light, we may reasonably hope to remove all dispute, which may arise, concerning their nature and reality (EHU 2.9, SBN 21-2)

This passage preserves in outline the structure of the analogous one from the Abstract. There are certain key points that appear in both. First, the "supposed" or "pretended" character is related to the faint and obscure nature of ideas, which, in turn, gives rise to an ambiguity that causes a series of problems. The ambiguity inherent in many ideas -expressed in the fact that some ideas can be confounded with similar ones- is transferred to the terms we attach to them. Second, Hume does not claim that the impressions that could have originated this supposed idea do not exist, but rather that we cannot "produce them" or "assign any," that is, we cannot find them. This implies that, while the situation persists, we cannot clarify the supposed idea and therefore we cannot disambiguate the term to which the idea is annexed. Thus, Hume might be suggesting that the term is not strictly empty but rather attached to an idea that remains unclear for the moment. In the passage from the first Enquiry this last option seems to be more forceful than that of the empty term. Certain qualifications Hume employs seem to direct us this way. In the first part, he says we use a term „without any distinct meaning, “ and we imagine it has annexed a "determinate idea " to it. The use of "distinct" and 
"determinate" indicates that the term lacks a precise meaning, rather than has no meaning at all, and that the idea attached to it is faint and obscure, but it is an idea after all. In the second part of the paragraph he takes up the same proposition although omitting the qualifiers "distinct " and "determinate." However, given their appearance in the first half of the paragraph it is highly plausible that Hume is referring to these kinds of terms and ideas. I suggest the sentence should be read along these lines: "When we entertain, therefore, any suspicion, that a philosophical term is employed without any [distinct] meaning or [determinate] idea (as is but too frequent), we need but inquire, from what impression is that supposed idea derived?"11

The text from the Enquiry seems to lead us towards a moderate interpretation of supposed ideas, since it suggests they are ideas and not empty terms. We can regard them as an extreme case of imperfect ideas, because they remain in a state of confusion or indistinctness, although this situation is not necessarily definitive. One of the advantages of this interpretation is that it preserves the regular use of the copy principle: if we consider that supposed ideas are ideas after all, the copy principle would apply to the relationship between ideas and impressions without forcing it into the linguistic level, a move which, on the other hand, would be difficult to justify.

\section{Fictions vs. supposed ideas}

If we give preference to the moderate interpretation of supposed ideas and admit they are ideas after all, why cannot they be considered fictions, as Garrett suggests? Before answering this question it is worth noticing, in the first place, that the criticism I made of Garrett's classification still stands because he poses that something consisting in "no idea at all“ can be a fiction. I provided textual evidence to show that this option is not plausible because fictions are (imperfect) ideas. In the second place, I have also shown that an idea can be imperfect for a number of reasons. Therefore, the fact that supposed ideas are imperfect does not necessarily imply they are fictions. What is the difference between a supposed idea and a fiction, then?

To begin, remember that the imperfect character of a fiction resides not in its incompleteness or imprecision, but in its impropriety: we consider that it represents something it could not have been copied from. Throughout the Treatise we find many examples of this kind, where Hume shows the real origin of these fictitious ideas and explains why it is improper to apply them to another context. I already mentioned the idea of duration without change and of substance, but other instances can be added: the perfect standard of equality (T 1.2.4.24, SBN 47-9), the distinct and continuous existence of

11 We would be facing a case similar to that of the idea of substance mentioned in footnote 7. When Hume states the proposition for the second time, he omits the qualifier "perfect" when referring to that idea, and says: "we have, therefore, no idea of a substance." 
objects ( $\mathrm{T}$ 1.4.2), or the Self ( $\mathrm{T}$ 1.4.6), to mention a few more. A supposed idea, on the other hand, is not an improper idea, but a radically imprecise idea, the obscurity of which cannot be dissipated so far. Let us review a couple of passages where Hume seems to suggest the difference between fictions and supposed ideas along these lines. In the first one, he is discussing the fiction of duration without change:

If it be a sufficient proof, that we have the idea of a vacuum, because we dispute and reason concerning it; we must for the same reason have the idea of time without any changeable existence; since there is no subject of dispute more frequent and common. But that we really have no such idea, is certain. For whence shou'd it be deriv'd? Does it arise from an impression of sensation or of reflection? Point it out distinctly to us, that we may know its nature and qualities. But if you cannot point out any such impression, you may be certain you are mistaken, when you imagine you have any such idea.

But tho' it be impossible to shew the impression, from which the idea of time without a changeable existence is deriv'd; yet we can easily point out those appearances, which make us fancy we have that idea. (T 1.2.5.28-29, SBN 64-5).

The first paragraph proceeds in the usual way, pointing out to the relationship between linguistic and mental levels. Hume argues that the fact of having the terms "vacuum" and "time without change" does not indicate we have adequate ideas of them. As in EHU 2.9, he omits the qualification "adequate" and simply says that „we have no such idea." So far, the procedure is similar to the one we saw at Abs. 7 and EHU 2.9. However, after suggesting the use of the copy principle to solve the issue, he says that „we can easily point out those appearances which make us fancy we have that idea." This means that, unlike supposed ideas, we can explain why the idea of duration without change is imperfect and by what means it was created. In the case of supposed ideas, there would be no explanation available.

Let us examine another example. In this case, Hume is dealing with the idea of necessary connection:

when we speak of a necessary connexion betwixt objects, and suppose, that this connexion depends upon an efficacy or energy, with which any of these objects are endow'd; in all these expressions, so apply'd, we have really no distinct meaning, and make use only of common words, without any clear and determinate ideas. But as 'tis more probable, that these expressions do here lose their true meaning by being wrong apply'd, than that they never have any meaning; 'twill be proper to bestow another consideration on this subject, to see if possibly we can discover the nature and origin of those ideas, we annex to them ( $T$ 1.3.14.14, SBN 162). 
Again, we find the same structure. Hume recognizes there is a term, „necessary connection", which represents an idea he considers imperfect (because it is not „clear and determinate"). Given this situation, we are presented with two options: either it is a term that has no distinct meaning (and we again notice the ellipsis of the qualifier "distinct" when he repeats the sentence, since it says "never have any meaning"), an option that would lead us to supposed ideas, or it lost its true meaning due to having been misapplied, which would mean the idea of necessary connection is a fiction. Hume believes we are faced with this last option and proceeds to explaining the mechanism that produced the fiction below. In presenting the disjunction, Hume says it is more likely that when we come across these problematic cases, we are dealing with fictions and not with supposed ideas. Is there any text where Hume not only suggests but also asserts that we are faced with ideas in a state of radical ambiguity? In the Dialogues, Philo presents an instance of this sort when discussing about degrees of qualities and circumstances:

But there is a species of controversy, which, from the very nature of language and of human ideas, is involved in perpetual ambiguity, and can never, by any precaution or any definitions, be able to reach a reasonable certainty or precision. These are the controversies concerning the degrees of any quality or circumstance (...) The disputants may here agree in their sense, and differ in the terms, or vice versa; yet never be able to define their terms, so as to enter into each other's meaning: Because the degrees of these qualities are not, like quantity or number, susceptible of any exact mensuration, which may be the standard in the controversy. That the dispute concerning Theism is of this nature, and consequently is merely verbal, or perhaps, if possible, still more incurably ambiguous, will appear upon the slightest enquiry (DNR 12.7, KS 217-8).

In this case, the radical ambiguity of ideas stem from the impressions they copy, because the latter cannot be expressed in precise units of measure. Philo says we can dispute endlessly ,whether Hannibal be a great, or a very great, or a superlatively great man, what degree of beauty Cleopatra possessed, what epithet of praise Livy or Thucidydes is intitled to, without bringing the controversy to any determination" (DNR 12.7, KS 217). In the Treatise Hume argues that we can intuitively recognize the degrees of a secondary quality such as weight, heat, colour or flavour when the difference between the compared objects is large ( $\mathrm{T}$ 1.1.5.7, SBN 15; 1.3.1.3, SBN 70) and even considers, as mentioned before, the fiction of a perfect standard for quantifiable items. But in the Dialogues, he is not referring to these kinds of qualities, but rather to others of a moral and aesthetic nature; and mainly to circumstances where we are comparing something known -the human mind- to something unknown -the divine mind (DNR 7.12, KS 218). This feature renders ideas that 
represent these kinds of qualities and circumstances imprecise and prevents reaching an agreement on their definition. If achieved, this agreement would guarantee the strict and uniform use of the terms we attach to those ideas. ${ }^{12}$

\section{Words and ideas}

Finally, I am going to deal briefly with the relation of linguistic and mental levels, which, as has become apparent, brings about consequences in the distinction between adequate and imperfect ideas. The difficulty in addressing this question is that Hume never systematically developed a theory of language (Powell 2013, 112; Ainslie 2010, 50). However, in general terms, it can be said that for Hume, every word with meaning must be related to an idea (Ott 2006, 235). We have already seen that Hume states ideas are „annexed“ to words. But in the light of what has been discussed, it is necessary to determine, firstly, whether meaning comes from an adequate idea only, or imperfect ideas can confer at least a minimum of intelligibility on the terms they are annexed to. Secondly, I will deal with the nature of the relation between words and ideas in order to elucidate whether it is indeed possible that there are "empty" terms strictly speaking, that is, detached from any idea, or, as I proposed earlier, these are terms connected with supposed ideas.

Regarding the first question, it can be contended that adequate ideas confer precision and uniformity to the terms connected with them, while obscure and imprecise ideas transfer their ambiguity to the terms they are attached to (EHU 7.2, SBN 60-1). Usually, Hume points out that ambiguity is greater or incurable when we deal with subjects that exceed our cognitive capacity (EHU 8.1, SBN 80-1), hence metaphysics is the usual domain where this kind of problems appears. An obvious case is that of the divine nature and attributes we saw earlier. But I also noted above that issues regarding degrees of certain empirical qualities, such as the greatness of Hannibal or the beauty of Cleopatra, seem hard to disambiguate. Furthermore, in the first Enquiry Hume indicates that this also takes place in the moral sciences because their objects are difficult to perceive: "the finer sentiments of the mind, the operations of the understanding, the various agitations of the passions, though really in themselves distinct, easily escape us, when surveyed by reflection" (EHU 7.1, SBN 60).

Hume suggests this kind of problem can be solved by "fixing" the meaning of ambiguous terms. This amounts to clarifying obscure ideas

12 Moral and aesthetic standards are particularly difficult to establish because they are grounded in feeling. Angela Coventry $(2006,120-133)$ argues it is possible to construct an ideal standard in these realms if we have a delicate imagination and go through a long process of observation, review, discussion and correction. This example shows that the state of radical ambiguity of supposed ideas is not definitive, since it is possible to find a way of clarifying them. 
attached to them via the copy principle. However, as I already noted, the use of the copy principle is limited. Consequently, Hume admits that we must not take for granted its application would lead us invariably to precise and uniform terms. That is why he is very cautious when describing his intentions: "We shall endeavour (...) to fix if possible the meaning of these terms, and thereby remove some part of that obscurity, which is so much complained of in this species of philosophy" (EHU 7.3, SBN 61-2). Why be so cautious regarding the chances of success of his endeavour? If we go back to the passages where Hume introduces supposed ideas, we will notice he points out ideas, especially complex and abstract ones, are by nature faint and obscure, in a way that "tis almost impossible even for the mind, which forms them, to tell exactly their nature and composition" (Abs. 7, SBN 6489). This inherent weakness and obscurity of ideas seriously complicates the methodological use of the copy principle, since if we cannot determine the precise structure of complex ideas, we are not in a position to exhaustively search for the impressions that caused them, which leads us to the difficulties mentioned above regarding adequate ideas. At the semantic level, it implies that the meaning of the terms connected to these ideas cannot be fixed with the utmost precision. In consequence, if the meaning of a word depended on the idea attached to it being adequate, then, strictly speaking, there would not be many meaningful words. Besides, in the passages where Hume talks about imperfect ideas, he does not regard the terms connected to them as completely meaningless, but as terms that do not have a determinate meaning. ${ }^{13}$ This meaning, although itself imperfect, guarantees a minimum of intelligibility that suffices to apply the copy principle to the imperfect idea they name and proceed with its clarification, at least, up to the point of recognizing the nature of its imperfection.

The faint and obscure nature of ideas gives rise to another difficulty. At EHU 2.9, SBN 21-2 Hume states that these features lead us to confuse ideas that are similar and, consequently, to use terms equivocally, believing that we name one idea when in fact we are naming another. This happens because usually, when we employ a term; we do not have in mind all the features of the idea it names, which would allow us to verify if it is indeed the same idea or a similar one. Thus, Hume observes that "we do not annex distinct and complete ideas to every term we make use of and that in talking of government, church, negotiation, conquest, we seldom spread out in our minds all the simple ideas, of which these complex ones are compos'd" ( $\mathrm{T}$ 1.1.7.14, SBN 23).

13 The only statement of something "completely " unintelligible occurs when Hume considers the notion of substance of ancient philosophy (T 1.4.3). However, in this case, he seems to point out that the very idea of substance was conceived as „something unknown and invisible, which it supposes to continue the same under all these variations" ( $T$ 1.4.3.4, SBN 220). This suggests that unintelligibility was an inherent quality belonging to the original notion of substance and not a problem pointed out by Hume. 
This leads us to the second question, regarding the nature of the connection between ideas and words. Hume explains that terms are usually confusing and ambiguous due to the fact that "we use words for ideas, because they are commonly so closely connected, that the mind easily mistakes them" (T 1.2.5.21, SBN 61-2). Here, Hume describes the relation between ideas and words as a close connection, although he does not further specify the nature of this connection. On the other hand, we have just seen he also points out that sometimes we must "fix" the meaning of the terms. In the same vein, when referring to the disputes caused by certain ambiguous terms, he indicates that "the disputants affix different ideas to the terms employed in the controversy" (EHU 8.1, SBN 80-1). These clues reveal that the close connection between ideas and words is "common", that is, general, but not always stable, since in some cases it needs to be properly fixed.

Walter Ott $(2006,236 ; 2009,205)$ suggests that Hume's theory of linguistic meaning can be understood in the light of the notion of sign he employs when explaining the principle of sympathy. This entails that words are signs that reliably indicate the speaker has a certain idea in mind: "the words or discourses of others have an intimate connection with certain ideas in their mind" (T 1.3.9.12, SBN 112-3). Also, it grants that exposing ourselves to the words of others causes similar ideas in us: "because such a particular idea is commonly annex'd to such a particular word, nothing is required but the hearing of that word to produce the corresponding idea" ( $\mathrm{T}$ 1.3.6.14, SBN 93) (Ott 2006, 241). Ott proposes, then, that we can suitably understand the connection between ideas and words as a type of causal relation (2006, 236). Moreover, this is suggested by Hume himself in the famous example of the murder of Caesar (T 1.3 4.2, SBN 83). What is the outcome of this interpretation? On the one hand, that there is a general correlation between ideas and words, a correlation that, like all causal relations, is regular but not necessary. On the other hand, the non-necessary character of the relation shows whence problems related to the ambiguity of terms arise: we usually join certain terms with certain ideas, but nothing prevents, in principle, that different connections can take place, or that the words we join to certain ideas be necessarily connected in the same way in other people's minds.

Now, understanding the connection between ideas and words in terms of a causal relation does allow for the existence of empty terms? Strictly speaking, nothing would prevent us from thinking about this possibility, since it is not contradictory. However, what I want to stress is that the semantic problems Hume deals with do not originate in the fact that the terms in question are literally empty. For example, when he says that it is necessary to "fix" the meaning of a term, he is not implying the term lacks an idea attached to it, but that it is connected to an imperfect idea. The same happens when he refers to verbal disputes. Hume does not suggest that these disputes originate because the terms are empty, but because the different participants attach different ideas to them. Thus, we can conclude that there are words with more stable 
meanings, for a number of reasons: they have a regular relationship with certain ideas, the ideas connected to them are simple, or point to recognizable matters of fact, etc. In sum, they are connected to an adequate idea. But there are other words whose meanings are more fleeting or unstable, because the ideas to which they are connected to are obscure, weak or confusing due to the reasons we have been discussing so far: they are abstract or general, such as "government" or "negotiation;" they are extremely complex, like the idea of Paris or a mite; they concern moral issues such as Hannibal's greatness; they refer to issues exceeding our cognitive capacity, such as the divine mind, etc.

\section{Conclusion}

I hope to have shown that, in the realm of ideas, things are not as simple as the distinction between genuine ideas and fictions suggests. Hume pays close attention to both regular cases and anomalous situations, which is evidenced by the fact that the latter are considered as much - if not more - than the former. An in-depth exam of both instances has revealed many details concerning relations between ideas and their objects. On the one hand, we have seen that ideas that can be regarded as adequate do not always fully capture their objects, but generally do so in a limited way. On the other hand, we have learned that imperfect ideas do not necessarily lead us to error, but rather produce imperfect and unfinished knowledge, and, at the semantic level, give rise to an ambiguity that is the source of disputes and misunderstandings. These shortcomings can be assessed but can only be fixed up to a certain point. In any way, both tasks are relevant: wheter revealing the workings of our imagination, or showing what are the limits of our cognitive skills.

\section{Bibliography}

Ainslie, Donald (2010). "Adequate Ideas and Modest Skepticism in Hume's Metaphysics of Space." Archiv für Geschichte der Philosophie 92, pp. 49-51.

-, (2015). Hume's True Skepticism. Oxford: Oxford University Press.

Costelloe, Timothy M. (2018). The Imagination in Hume's Philosophy: The Canvass of the Mind. Edinburgh: Edinburgh University Press.

Coventry, Angela (2006). Hume's Theory of Causation: A Quasi-Realist Interpretation. London: Continuum.

Garrett, Don (1997). Cognition and Commitment in Hume's Philosophy. Oxford: Oxford University Press.

Garrett, Don (2006). "Hume's Naturalistic Theory of Representation." Synthese 152, pp. 301-319. 
Hume, David (1739-40/2007). A Treatise of Human Nature, edited by David Fate Norton and Mary J. Norton [T]. Oxford: Oxford University Press $\left(1^{\text {st }}\right.$ ed., 2000). Cited by book, part, section, paragraph and page number in L. A. Selby Bigge's edition revised by P. H. Nidditch.

-, (1740/2007). "An Abstract of a Book Lately Published: Entituled, A Treatise of Human Nature, etc. Wherein the Chief Argument of that Book is farther Illustrated and Explained" [Abs.] In A Treatise of Human Nature, edited by David Fate Norton and Mary J. Norton. Oxford: Oxford University Press $\left(1^{\text {st }}\right.$ ed., 2000). Cited by paragraph and page number in L. A. Selby Bigge's edition revised by P. H. Nidditch.

-, (1748/1999). An Enquiry Concerning Human Understanding, edited by Tom L. Beauchamp [EHU]. Oxford: Oxford University Press. Cited by section, paragraph and page number in L. A. Selby Bigge's edition revised by P. H. Nidditch.

-, (1779/1947). Dialogues Concerning Natural Religion, edited with an introduction by Norman Kemp Smith [DNR]. Indianapolis: BobbsMerrill. Cited by part, paragraph and page number in Kemp Smith edition.

Kail, Peter (2003). "Conceivability and Modality in Hume: A Lemma in an Argument in Defense of Skeptical Realism." Hume Studies 29 (1), pp. 43-61.

Landy, David (2018). Hume's Science of Human Nature. Scientific Realism, Reason, and Substantial Explanation. New York: Routledge.

Lightner, D. Tycerum (1997). "Hume on Conceivability and Inconceivability." Hume Studies 23 (1), pp. 113-132.

Locke, John (1689/1975). An Essay Concerning Human Understanding, ed. P. H. Nidditch [E]. Oxford, Clarendon Press. Cited by book, chapter and section. Ott, Walter (2006). "Hume on Meaning." Hume Studies 32 (2), pp. 133-252.

-, (2009). Causation and Laws of Nature in Early Modern Philosophy. Oxford: Oxford University Press.

Powell, Lewis (2013). "How to Avoid Mis-Reiding Hume's Maxim of Conceivability." The Philosophical Quarterly 63 (250), pp. 105-119.

Richman, Kenneth N. (2000). "Introduction," in Read, Rupert and Richman, Kenneth N. The New Hume Debate. London: Routledge, pp. 1-15.

Traiger, Saul (1987). “Impressions, Ideas, and Fictions." Hume Studies 23 (2), pp. 381-399. 